\title{
Restoring hearing symmetry with two cochlear implants or one cochlear implant and a contralateral hearing aid
}

\author{
Jill B. Firszt, PhD; ${ }^{*}$ Ruth M. Reeder, MA; Margaret W. Skinner, $\mathbf{P h D}^{\dagger}$ \\ Department of Otolaryngology-Head and Neck Surgery, Washington University School of Medicine, St. Louis, MO
}

\begin{abstract}
With today's technology and the demonstrated success of cochlear implantation, along with expanded candidacy criteria, the opportunity to provide optimal hearing to both ears for individuals with severe-to-profound hearing loss is greater than ever. This article reviews the advantages of binaural hearing and the disadvantages of hearing with only one ear or hearing with two ears with significantly different sound thresholds. A case study is presented that demonstrates the benefit of bimodal hearing (i.e., a cochlear implant [CI] in one ear and a contralateral hearing aid [HA]) in a nontraditional CI candidate with asymmetrical hearing thresholds. Then, selected studies in adult recipients who use a CI and contralateral HA or who use two CIs are summarized. The data overall demonstrate that bilateral CI recipients, traditional bimodal recipients, and nontraditional bimodal recipients experience substantial binaural hearing advantages, including improved speech recognition in noise, localization, and functional everyday communication. These results indicate that bilateral stimulation of the auditory system through a CI and contralateral HA or two CIs is beneficial and should become standard clinical practice.
\end{abstract}

Key words: asymmetrical hearing loss, bilateral, bimodal, binaural hearing, binaural squelch, binaural summation, cochlear implant, head shadow effect, hearing aid, localization, rehabilitation, speech recognition.

\section{INTRODUCTION}

Normal-hearing individuals typically hear with both ears and have auditory thresholds that are similar between the two ears. When a bilateral symmetrical sen- sorineural hearing loss occurs, the auditory system has reduced acoustic input, yet a balance exists between acoustic inputs to the two ears. However, many people manage in daily life with noticeable asymmetry in hearing. Asymmetrical hearing can occur when acoustic thresholds are different between ears, when only one cochlear implant (CI) is used, or when only one hearing aid (HA) is fit to a person with a bilateral symmetrical hearing loss.

Abbreviations: $\mathrm{APHAB}=$ Abbreviated Profile of Hearing Aid Benefit; $\mathrm{C}=$ constant error values; CCITT = Comité Consultatif International Téléphonique et Télégraphique; $\mathrm{CI}=$ cochlear implant; CIS = continuous interleaved sampling; $\mathrm{CNC}=$ consonant-nucleus-consonant; CST $=$ Connected Speech Test; CUNY = City University of New York; DAI = direct audio input; HA = hearing aid; HINT = Hearing in Noise Test; HiRes = HiResolution; IC = inferior colliculus; ILD = interaural level difference; ITD = interaural time difference; $\mathrm{MAA}=$ minimal audible angle; $\mathrm{PDT}$ = peak derived timing; $\mathrm{RMS}$ = root-meansquare; SII = Speech Intelligibility Index; SNR = signal-tonoise ratio; $\mathrm{SPL}=$ sound pressure level; $\mathrm{SRT}=$ speech reception threshold; SSQ = Speech, Spatial, and Qualities of Hearing Scale.

*Address all correspondence to Jill B. Firszt, PhD; Washington University School of Medicine-Otolaryngology, 660 South Euclid Avenue, Campus Box 8115, St. Louis, MO 63110; 314-362-4760; fax: 314-362-4436.

Email: firszti@ent.wustl.edu

${ }^{\dagger}$ Dr. Skinner died January 11, 2008.

DOI: 10.1682/JRRD.2007.08.0120 
When patients use bimodal stimulation (i.e., a CI in one ear and an HA in the other) or bilateral CIs, they may be able to restore a degree of symmetry between the two sides of the auditory pathway. In this article, we discuss the effects of symmetrical and asymmetrical hearing loss on the auditory system. A case study is presented that demonstrates the benefit of bimodal stimulation in a nontraditional CI candidate with asymmetrical hearing thresholds. Selected studies are reviewed to illustrate the improvements in speech recognition, localization, and functional everyday communication in individuals who use bimodal stimulation (summarized in Appendix 1, available online only at http://www.rehab.research.va.gov/jour/ 08/45/5/pdf/contents.pdf) or are recipients of bilateral CIs (summarized in Appendix 2, available online only at http:// www.rehab.research.va.gov/jour/08/45/5/pdf/contents.pdf) [1-4]. The opportunity to provide audible cues to both ears is greater than ever given today's CI and HA technology. To the extent possible, bilateral symmetrical acoustic input is highly encouraged.

\section{IMPORTANCE OF BINAURAL HEARING}

Binaural hearing is a fundamental property of the normal auditory system. In real-life listening situations, conversation often occurs in the presence of background noise, primarily in rooms where other people are talking. If there is more than one talker, understanding speech requires the ability to locate and follow each one. Many individuals with hearing loss in one or both ears have difficulty with this situation. Evidence for binaural benefits when both ears are stimulated compared with stimulation of one ear alone are well documented in normal listeners [5]. For example, when subjects listen to monaural compared with binaural pure tones at suprathreshold levels, the stimulus in the monaural ear must be 6 to $10 \mathrm{~dB}$ higher than the stimulus during binaural presentation to result in equal loudness judgments [6-7]. This effect, binaural loudness summation (or binaural redundancy), results in signals being louder when subjects listen with both ears than with one ear. With bilateral signal presentation, there is redundancy in the information and, subsequently, an enhanced sensitivity to small changes in intensity and frequency that contribute to improved detection and/or speech recognition [8]. This effect also plays a role when speech and noise come from the same source; thus, with binaural hearing, redundancy cues enhance speech-recognition performance in noise. In CI studies, binaural loudness summation effects are typically determined by comparing percent-correct scores on a speech-recognition measure obtained in the bilateral condition (CIs on both sides) and one unilateral condition (one CI on the right or left side) in which speech is presented from the front in quiet or speech and noise are presented from the front.

When speech and noise are spatially separated, the head shadow effect creates another binaural benefit, since each ear has a different signal-to-noise ratio (SNR) because of the physical placement of the head. Typically, the SNR at the ear furthest from the noise is increased as a result of attenuation of high-frequency sounds in the noise, which can result in 8 to $10 \mathrm{~dB}$ of improvement in normal-hearing subjects [8-9]. The effect size varies, however, and can be as small as $3 \mathrm{~dB}$, depending on the distance between the target and noise sources (i.e., larger separation of sources results in greater effects), as well as the number of stimuli in the target and types and number of noise sources (e.g., pink noise, speech-spectrum noise). In CI studies, head shadow effects typically are determined by comparing percent-correct scores on a speechrecognition measure obtained in the unilateral condition (right or left) in which noise is presented on the same side of the implant and the opposite (contralateral) side. In a unilateral condition, moving the noise from the implant side to the opposite side creates the head shadow effect.

Another benefit of binaural hearing, the binaural squelch effect (or the binaural unmasking or binaural release from masking effect), is thought to reflect central auditory system analyses that occur by comparing interaural level differences (ILDs) and interaural time differences (ITDs) between the two ears. Hearing in noise is improved by adding the ear closest to the noise source and by using timing and phase difference cues between ears if the signal and noise come from different directions. The effect is a $3 \mathrm{~dB}$ improvement for a binaural intelligibility level difference of 50 percent correct using monosyllabic words [10]. In CI studies, binaural squelch effects typically are determined by comparing percentcorrect scores on a speech-recognition measure obtained in the unilateral condition, in which noise is on the opposite side of the implanted ear, with those obtained in the bilateral condition, in which noise is on the same side. For example, the left unilateral condition with noise on the right is compared with the bilateral condition with noise on the right. 
The analysis of both ILD and ITD cues contribute to sound localization, the listener's ability to identify the location of a sound source in his or her horizontal plane. ILD cues are necessary for localization of high-frequency sounds (above approximately $1500 \mathrm{~Hz}$ ), whereas ITD cues provide information for low-frequency sounds (less than $1500 \mathrm{~Hz}$ ). Normal-hearing listeners can resolve small intensity differences of 0.5 to $2.5 \mathrm{~dB}$ depending on the sound intensity and frequency [11] and can discern signals to within 1 to $2^{\circ}$, or an equivalent ITD of 10 to $15 \mu$ s. In CI studies, localization abilities are typically determined by comparing the root-mean-square (RMS) error or minimal audible angle (MAA) values obtained in the unilateral condition with those of the bilateral condition.

Each of the described binaural effects improves speech recognition, particularly in noise, with binaural compared with monaural listening in normal-hearing subjects. Whereas the head shadow effect is a physical phenomenon due to the placement of the head, binaural loudness summation, binaural squelch, and localization require integration by the central auditory system. When changes occur to the central auditory system as a result of the absence of input, the normal binaural processes are disrupted.

\section{EFFECTS OF SYMMETRICAL PROFOUND HEARING LOSS ON THE AUDITORY SYSTEM}

Profound sensorineural hearing loss in both ears deprives the auditory system of acoustic input. In animal studies, deafness induced with ototoxic drugs or highlevel sounds results in degeneration of cochlear hair cells, primary afferent spiral ganglion neurons, and corresponding central axons [12-13]. In human subjects who had postlingual onset of bilateral profound hearing loss, changes in cell size have been observed in the cochlear nucleus (anterior division), superior olivary nucleus (medial portion), and inferior colliculus (IC) [14]. Animal studies support a critical period during development in which deprivation at a young age causes greater, and sometimes irreversible, damage than does deprivation at a later time [15-17]. In young animals and across many species, sound deprivation results in decreased neuronal size, volume, and number in the cochlear nucleus. Animal models of congenital deafness provide a means of studying the effects of hearing loss on development without cochlear ablation or experimentally induced deafness.
Studies in the congenitally deaf white cat reveal that synapses of auditory nerve endings are abnormal, such as between end bulbs of Held and spherical bushy cells [1820], as well as between modified end bulbs and globular bushy cells [21]. In addition, the synaptic abnormalities are present at an early age (6 months) in the deaf white cat. It is important to consider these findings and their relevance to individuals with prelingual severe-toprofound hearing loss who consider cochlear implantation in adulthood. That is, bilateral profound hearing loss clearly has degenerative effects on the central auditory system and longer periods of congenital auditory deprivation have greater consequences than shorter periods of deafness or onset of hearing loss at an older age.

\section{EFFECTS OF ASYMMETRICAL HEARING LOSS ON THE AUDITORY SYSTEM}

Asymmetrical auditory deprivation can result in more extensive morphological changes than bilateral deprivation. For example, the effects of unilateral and bilateral auditory deprivation on changes in IC unit activity have been investigated by varying the relative intensities of click stimuli presented to the two ears. Unilateral ligation of the external auditory meatus in 10-day-old rats that were then deprived of sound for 3 to 5 months showed that ipsilateral suppression was not evident in the IC ipsilateral to the deafened ear. In addition, the contralateral IC received activity that was either reduced from the deprived ear, had increased suppressive input from the undeprived ear, or both [22]. In contrast, the effects of 3 to 5 months of symmetrical sound deprivation in rats that were binaurally deprived of sound (through bilateral ligation at 10 days of age) showed that binaural interaction was essentially normal. In other words, binaural interaction in the IC was more negatively affected by asymmetrical input between ears than by bilateral symmetrical deprivation. These results in the IC have been confirmed by others [23] and also shown in the auditory cortex [24-25].

With bilateral hearing loss, auditory inputs to the two ears are balanced and little to no competition exists among inputs for neuronal targets [22-23,26-27]. Likewise, in the visual system, bilateral deprivation results in a decrease in activity, yet a normal balance of binocularly driven cells exists [28-29]. In contrast, when hearing is not symmetrical (e.g., asymmetrical hearing loss or unilateral CI use), competition between neuronal targets occurs 
because of an imbalance between active and inactive inputs to neurons that receive binaural projections. In this case, binaural inputs are in competition with neuronal targets, inactive regions will be replaced by those with greater activity, and reorganization to the central auditory system occurs in ways that are different from symmetrical severe-to-profound hearing loss [22-23,27, 30-32].

This competitive interaction and the need for balanced input between the ears could affect the development of the binaural auditory system [32-35]. To date, the amount of stimulation needed from each ear for normal development of the binaural auditory system in humans is unknown. Early studies in the visual system of the cat [28] and monkey [36] showed that development of binocularly sensitive neurons required early binocular vision. Binocularly driven cells were reduced in immature animals when one eye was sutured closed or stereo vision was unavailable [28,37]. In animals and humans, unit activity in the IC of the auditory system is believed to reflect binaural interaction activity in the brain stem. Peripheral effects have not accounted for the changes in binaural interaction, implicating alteration of the central auditory system during early development. These findings have important implications for adults with asymmetrical hearing over long periods of time and/or from an early age, the effects of which may be quite different.

\section{INCIDENCE OF ASYMMETRICAL HEARING LOSS AND PERCEIVED HANDICAP}

Asymmetrical hearing may occur in a number of ways. For example, cochlear implantation in one ear results in asymmetrical hearing, since the implanted ear detects and recognizes speech at normal conversational levels, whereas the other ear does not. Asymmetrical hearing for periods of time between sequentially implanted ears could play a substantial role in auditory experience and function. Asymmetrical hearing can result from differing acoustic thresholds between ears. Finally, asymmetry can be created when unaided acoustic thresholds are symmetrical but amplification is worn in one ear. The various scenarios in which asymmetrical hearing might exist make determining the prevalence in the adult population difficult. Prevalence rates also vary based on the criteria used to define asymmetry. Noble and Gatehouse report that 33 percent of patients have asymmetrical hearing loss, which they defined as an interaural difference of more than $15 \mathrm{~dB}$ in thresholds averaged at 0.5 to $4 \mathrm{kHz}$ [38]. This prevalence is consistent with previous reports [39-40] but somewhat higher than that reported by Pittman and Stelmachowicz [41], who defined asymmetry as $>20 \mathrm{~dB}$.

Asymmetry in hearing negatively affects spatial hearing (e.g., direction, distance, movement) and is associated with reduced naturalness/sound quality and signal segregation as well as with increased effort during communication [38]. In two groups of patients, one with asymmetrical hearing loss and the other with symmetrical hearing loss, the asymmetrical group was more disabled based on self-ratings on the Speech, Spatial, and Qualities of Hearing Scale (SSQ) [42]. The symmetrical group was more uniform in their ratings of their disability, whereas the asymmetrical group's disabilities were more selective. For example, specifically noted as difficult were situations that required rapid switching of attention or in which no options existed for physically repositioning oneself for improved listening, either in quiet or in a noisy room. Individuals with asymmetrical hearing loss could function adequately when the environment was static but not when the environment was dynamic.

\section{ASYMMETRICAL HEARING CREATED BY MONAURAL AMPLIFICATION}

A series of studies investigated the effects of monaural HA fitting in individuals with symmetrical bilateral sensorineural hearing loss. In the earliest of reports, Silman and colleagues showed that the word-recognition scores of the unaided ear of veterans with bilateral symmetrical hearing loss when fit unilaterally decreased significantly over 4 to 5 years, while the aided ear maintained performance [43]. Individuals using binaural amplification or no amplification did not show an interaural difference. This finding was referred to as "lateonset auditory deprivation" and was further substantiated by other studies [44-46], as well as by studies in children [47-48]. Evidence that effects of auditory deprivation are associated with amplification fit to only one ear were supported by the 1995 Eriksholm Workshop on Auditory Deprivation and Acclimatization [49]. Asymmetry in the stimulation of the auditory pathways is thought to contribute to late-onset auditory deprivation.

Gatehouse introduced a hypothesis of acclimatization for the aided ear rather than one of auditory deprivation for the unaided ear alone [45]. Word-recognition-in-noise scores at presentation levels between 65 and $90 \mathrm{~dB}$ sound 
pressure level (SPL) were compared in 24 monaurally aided subjects. Results at the highest intensity levels replicated those of Silman et al. [43] and Gelfand et al. [44], such that the aided ear performed better than the unaided ear. In contrast, at lower levels the finding was the opposite. That is, the aided ear performed more poorly at lower intensities than the unaided ear, presumably because of acclimatization of processing speech at higher intensities. A weakness in this study was that no information was available about the subjects' word-recognition abilities before the fitting of monaural HAs. Evidence of symmetrical function between the two ears before the fitting of amplification was not offered. To address this limitation, Gatehouse investigated four subjects with documented symmetrical hearing loss before and after monaural HA fitting [50]. As expected, significant increases in benefit for the HA ear were noted compared with the unaided ear. In addition, the benefits required at least 6 to 12 weeks. Their data supported both an acclimatization effect for the aided ear and a deprivation effect for the unaided ear. In 1990, Silverman and Silman showed evidence in two subjects that the late-onset auditory deprivation effect from unilateral amplification could be reversed with later bilateral amplification [51], although in other investigations, some recovery and no recovery occurred [52]. The success of both HAs and CIs relies on how the auditory system responds to the introduction of new sounds either acoustically, electrically, or a combination of the two and on the subsequent acclimatization to these sounds over time.

\section{RESTORATION OF SYMMETRICAL HEARING WITH BIMODAL LISTENING: COCHLEAR IMPLANT AND CONTRALATERAL HEARING AID IN NONTRADITIONAL IMPLANT CANDIDATES}

Typical CI candidates have severe-to-profound hearing loss in both ears. Persons who have only one ear with severe-to-profound hearing loss and the other ear with more hearing have not been considered CI candidates. One assumption is that the individual will perform sufficiently well with conventional amplification in the better ear alone. A weakness in this assumption is that fitting of amplification in one ear does not optimize binaural function, since sounds are most likely heard in only the better ear, again removing the interaction between ears. Consequently, these individuals continue to function with only unilateral auditory input. Provision of some bilateral cues (head shadow) to patients with asymmetrical hearing loss has been attempted with Bi-Cros (contralateral routing of signals) HAs [53]. With this HA arrangement, microphones placed on both ears amplify and send the bilateral input to the better hearing ear alone. Sounds at the poorer ear are received and detected at the better ear, but this does not constitute true binaural input. In our clinical experience, patients may report improvements in specific listening situations with a Bi-Cros HA, for example, in the car when the passenger is on the side of their deaf ear; however, in general, they continue to struggle in many everyday communication situations.

Individuals with asymmetrical sensorineural hearing loss may receive significant binaural benefit from having a CI placed in the poorer ear along with an HA in the better ear. Preliminary data are shown in Figures $\mathbf{1}$ and $\mathbf{2}$ for a patient from Washington University who has had an asymmetrical hearing loss of unknown origin for $>20$ years. Her hearing thresholds were between 55 and $75 \mathrm{~dB}$ hearing level from 250 through $8000 \mathrm{~Hz}$ in a mildly sloping configuration in the right ear and in the severe-toprofound range in the left ear. Because of the asymmetry between ears, she had discontinued amplification in the left ear before study enrollment. She was implanted in the poorer ear (i.e., left ear) at the age of 68. Statistically

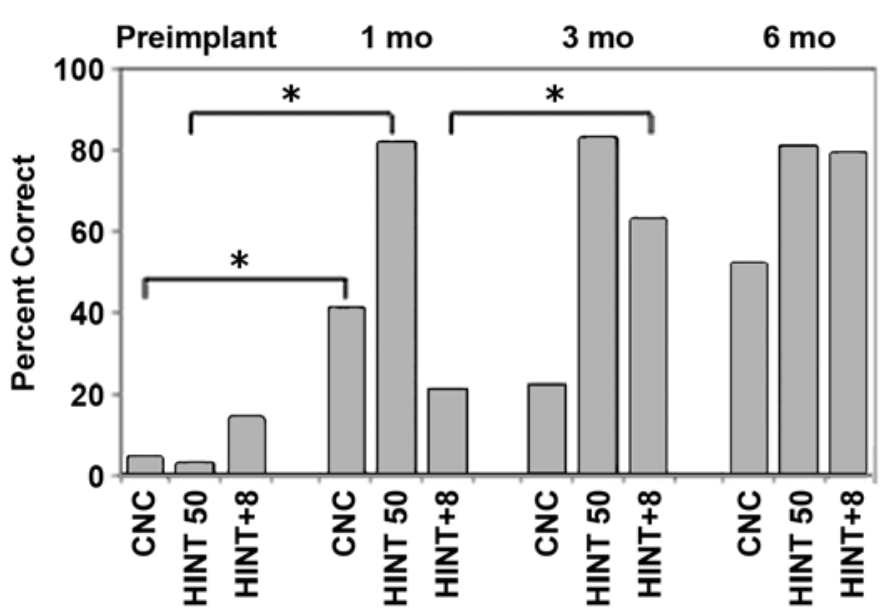

Figure 1.

Word- and sentence-recognition scores for one patient's left ear at four test intervals from preimplant to 6 months postimplant. Tests were consonant-nucleus-consonant (CNC) words at $60 \mathrm{~dB}$ sound pressure level (SPL), Hearing in Noise Test (HINT) sentences in quiet at $50 \mathrm{~dB}$ SPL (HINT 50), and HINT sentences in noise at $60 \mathrm{~dB}$ SPL and $+8 \mathrm{~dB}$ signal-to-noise ratio with four-talker babble $(\mathrm{HINT}+8)$. * Significant differences $(p<0.05)$ on specific measures between test intervals. 

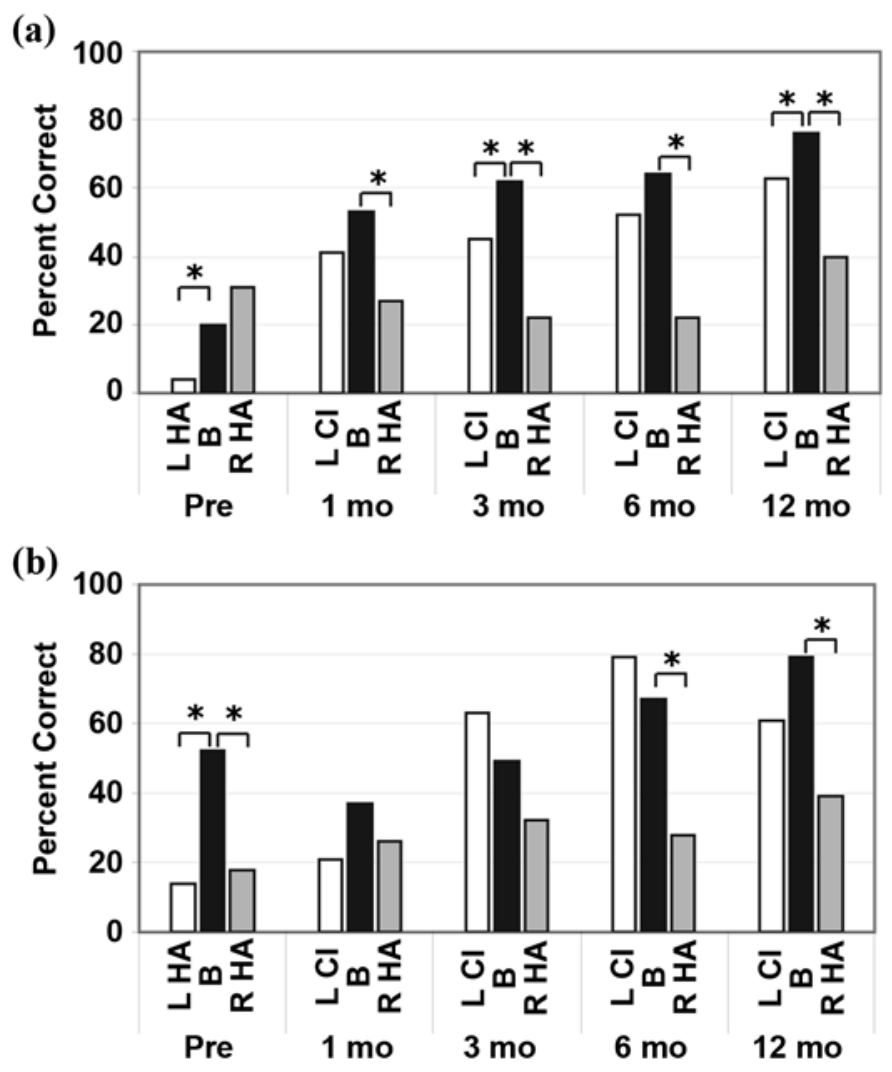

Figure 2.

(a) Word-recognition scores (consonant-nucleus-consonant) and (b) sentence-recognition scores (Hearing in Noise Test sentences in noise) at test intervals from preimplant (Pre) to 12 months postimplant. Test condition is displayed on $x$-axis at each interval. Preimplant scores reflect left ear aided (L HA, white bar), bilateral hearing aids (B, black bar), and right ear aided (R HA, gray bar). Postimplant scores (1, 3, 6, and 12 months) reflect left ear implanted (L CI, white bars), bimodal condition of implant plus hearing aid (B, black bars), and right ear with moderate hearing loss aided (R HA, gray bars). *Significant differences $(p<0.05)$ in unilateral versus bilateral performance.

significant differences in test scores were determined with a binomial model at the 0.05 level.

In Figure 1, speech-recognition scores are shown for the left ear at preimplant through 6 months postimplant. At the preimplant test interval, scores are quite low for all three measures (4\% on consonant-nucleusconsonant [CNC] words, 3\% on Hearing in Noise Test [HINT] sentences in quiet, $14 \%$ on HINT sentences in noise). At 1 month postimplant, scores are substantially increased for tests in quiet: 41 percent on CNC words and 82 percent on HINT sentences. Performance for sentences in noise improves to 21,63 , and 79 percent at 1,3 , and 6 months postimplant, respectively.
In Figure 2, performance in the right ear remains relatively stable over time for CNC word recognition. Some fluctuation in scores is observed for the HINT sentences in noise measure, with an improvement of 21 percentage points between preimplant and 12 months postimplant. In the left ear and bilateral condition for CNC words, an immediate improvement is seen at 1 month postimplant, followed by subsequent increases in score at later intervals. A small bilateral improvement is noted compared with the implanted ear across time. For HINT sentences in noise, a slight decrease in the bilateral score is noted at 1 month postimplant, but performance returns to preimplant level at 3 months postimplant, with a further increase after 12 months of use to 79 percent correct. Note that the left ear is now the better performing ear after being the poorer ear for more than 20 years.

The clinical scores are supported by this patient's subjective experience. The SSQ is a comprehensive inquiry of hearing disabilities, includes a broad range of domains, and is intended to reflect listening in real-world situations [42]. The Speech scale assesses hearing of speech in competing contexts such as reverberation and multiple talkers. The Spatial scale addresses directional and distance hearing. The Qualities scale concerns segregation of sounds, naturalness and clarity, and listening effort. Each item is rated on a continuum of 0 to 10, and higher scores reflect greater ability. Figure 3 shows scores for this patient from preimplant to 12 months postimplant. Scores for all three scales increase substantially through 3 months, followed by slight increases through 12 months. This patient is extremely pleased with the CI in her poorer ear. As we research the effects of cochlear implantation in an ear with severe-to-profound hearing loss for individuals with better hearing in the contralateral ear, we will determine the relation between hearing in each ear on speech-recognition outcomes and benefits in real-life situations, as well as whether binaural processing can be achieved with acoustic and electric hearing for these candidacy profiles.

\section{RESTORATION OF SYMMETRICAL HEARING WITH BIMODAL LISTENING: COCHLEAR IMPLANT AND CONTRALATERAL HEARING AID IN TRADITIONAL IMPLANT CANDIDATES}

\section{Speech Recognition}

In this section, we review studies of traditional CI candidates who meet current candidacy criteria and 


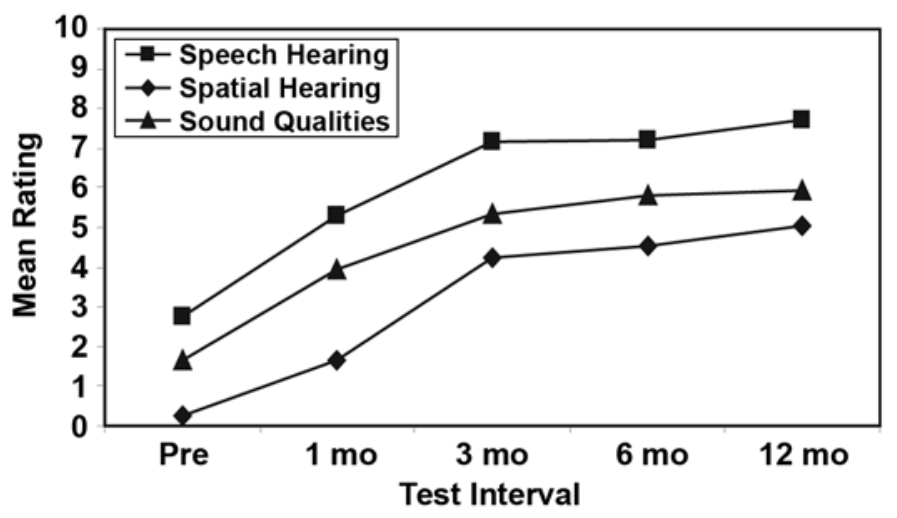

Figure 3.

Scores (0-10 rating) for one individual on each of three subsections of the Speech, Spatial, and Qualities of Hearing Scale at four test intervals from preimplant (Pre) to 12 months postimplant. Significant improvements in ratings (at $p<0.05$ or greater) were present between all test intervals except for postimplant comparisons of 3 and 6 months on Speech Hearing scale and 6 and 12 months on Spatial Hearing scale.

receive a $\mathrm{CI}$ in one ear and continue to wear a contralateral HA (summarized in Appendix 1). Previously, unfounded apprehension existed concerning bimodal arrangements, since little was known about the integration of electric stimulation in one ear with acoustic stimulation in the other. Early reports suggested that listening with a CI and an HA might be better than listening with either device alone [54-55]. These two inputs apparently can be combined successfully and provide beneficial binaural hearing [56-63]. In a small sample, speech recognition in quiet and noise was reported for three subjects who had used a CI and an HA for more than 5 years [64]. A binaural advantage was noted for two of the three patients when speech and noise were delivered from a front location. The patient with the least notable bilateral benefit also had the least benefit from the amplification side. Although the results varied across patients and test measures and the sample size was small, binaural benefits were seen on some measures. Bimodal improvements in listening have been documented in larger samples of adults, particularly for speech recognition in the presence of noise. In a study with 21 adult CI recipients [57], speech recognition was greater in the bimodal than the implant-only condition when the speech and noise were presented from the front (+10 dB SNR) and when speech was presented at $60^{\circ}$ toward the side with the HA and noise presented $60^{\circ}$ toward the side with the implant $(+10$ and $+15 \mathrm{~dB}$ SNR). Significant improvements were noted for the group and for individual study participants. The few who did not demonstrate improvement in the bimodal condition had similar performance in the implantonly and bimodal conditions.

Low-frequency residual hearing contributes to pitch perception and could play an important role in the perception of speech in noise and in music recognition. In a study of five bimodal listeners, the addition of the HA with the CI significantly improved speech recognition in noise, even though the HA-alone condition resulted in little speech recognition [60]. Evaluation of melody recognition in the same subjects resulted in superior scores in the HA-alone condition than in the implant-alone condition. Therefore, the HA alone appeared to provide some melody recognition but not speech recognition in noise, while the CI alone provided some speech recognition in noise but not melody perception. The authors concluded that low-frequency, fine-structure cues evoked acoustically and combined with low-frequency envelope cues provided electrically resulted in the observed improvements in speech recognition in noise.

Individual performance varies both within and across studies. Twelve adults participated in measures of speech recognition that included CNC words in quiet and City University of New York [CUNY] sentences in multitalker babble with customized SNRs for each subject to avoid ceiling and floor effects [58]. Significant bimodal benefits were shown for the head shadow effect (8 of 11 subjects), the binaural summation effect (4 of 12 subjects on CNC words, 7 of 11 subjects on CUNY sentences in noise with speech and noise from the front), and the binaural squelch effect (6 of 10 subjects). For the sentence testing, a bimodal disadvantage was seen for two subjects with speech and noise from the front and for one subject when the speech and noise were separated with noise toward the CI side. Interestingly, the individuals who demonstrated a disadvantage when the speech and noise were both from the front had a bimodal advantage when the speech and noise were separated. Likewise, the individual who had a bimodal disadvantage when the speech and noise were separated had a significant bimodal advantage when the speech and noise were both from the front. None of the participants had a bimodal disadvantage when the noise was presented from the side of the HA.

A significant study design concern is that ceiling effects may prevent the observance of bimodal benefit, particularly for sentences or stimuli presented in the quiet condition [58,62]. In a multicenter study with 12 adults 
[61], a bimodal advantage was not demonstrated for sentences in quiet (at 70 and $55 \mathrm{~dB}$ SPL) but was present for words at the same presentation levels (70 and $55 \mathrm{~dB}$ SPL). Ceiling effects with the sentence material prohibited evidence of a bimodal benefit. Group results of seven adults who had a wide range of residual hearing in the nonimplanted ear supported a bimodal advantage in quiet for numbers, monosyllabic words, and sentences [59]. Even though the group data supported a bimodal advantage in quiet, the individual results showed that ceiling effects limited the study findings for the numbers and sentences measures.

Bilateral use of a CI and an HA requires compensation for loudness summation effects and equalization of loudness compared with the fitting of each device alone. Blamey and colleagues studied nine subjects who were implanted in one ear with five electrodes. They showed that the shapes of loudness growth functions for five acoustic frequencies were similar to those obtained with five implanted electrodes, although the shapes of the respective curves and the dynamic ranges varied [65]. Loudness summation occurred when both devices were turned on and particularly when the signals (i.e., acoustic and electric) were balanced for equal loudness. In a recent study by Potts [66], subjects were carefully fit with digital power HAs with low compression thresholds (Widex Senso Vita 38) in one ear and wore a CI (Nucleus 24 device) in the other. HAs were fit to achieve maximum audibility and comfort for loud sounds within the acoustic dynamic range. The Verifit system was used at three input levels to confirm optimal HA settings for each subject and to calculate the Speech Intelligibility Index (SII). CIs were fit to achieve maximum audibility and comfort for loud sounds within the electric dynamic range by using procedures developed at Washington University by Skinner and colleagues [67-69]. Device settings were further adjusted for bimodal wear. Significant predictors of both speech recognition and localization were associated with variables related to audibility of sound in the nonimplanted ear, such as unaided hearing thresholds $(1500,2000,3000$, and $4000 \mathrm{~Hz})$ and aided frequencymodulated tone thresholds (1500 and $2000 \mathrm{~Hz}$ ). In addition, the SII scores at all three tested inputs were significant predictors of speech recognition and localization scores, suggesting that the HA must be optimally fit at all input levels to maximize performance.

By contrast, Ching and colleagues did not identify a correlation between unaided hearing thresholds (250, 500 , and $1000 \mathrm{~Hz}$ ) in the acoustic ear and bimodal bene- fit in a group of 21 bimodal adults [57]. The subjects in their study had poorer unaided thresholds (aided thresholds were not reported) than those in Potts' study [66]. The HA fitting procedures also differed between the two studies. In another recent study with 14 bimodal adults, those with poorer aided thresholds in the mid-to-high frequency range had greater bimodal benefits [62]. These results suggest that acoustic information in the mid-tohigh region via the HA might interfere with binaural effects rather than enhance them. The varied findings from these studies highlight the importance of optimal procedures for fitting an HA and a CI to maximize bimodal performance.

Some studies indicate that subjects who have regularly worn an HA obtain higher scores in the bimodal condition than those who have less regular HA use [70]. Others have documented that bimodal improvements in listening have occurred even in cases when an HA is introduced later to the nonimplant ear [57]. For Ching and colleagues [57], results were mixed; no significant differences were found in bimodal benefits between new and experienced HA users for speech from the front and noise from the implant side. When speech and noise were presented from a single loudspeaker, new HA users obtained better scores than those with experience. Across studies, most subjects report a favorable improvement in sound with bimodal listening, such as more natural sound quality [70], more balanced sound quality that is louder [66], enhanced music enjoyment, easier listening in background noise, and increased confidence in everyday situations [57].

\section{Localization}

The ability to localize sound is important in daily living; for example, being able to locate important sound sources in the environment for safety reasons. Participation in conversation with multiple talkers requires finding each speaker relatively quickly as ideas are communicated from one person to the next. A common perceptual difficulty when listening with one ear (or one implant) is locating a sound source. It stands to reason that individuals may have improved sound localization abilities when fit with bimodal devices. In an early report of three subjects who used a CI and contralateral HA for more than 5 years [64], a three-loudspeaker setup was used with loudspeakers from the front and $45^{\circ}$ to the right and left of the listener. Two of the three patients demonstrated improvements in left/right localization when listening with both devices. Studies conducted at the National Acoustic 
Laboratories in Australia used an 11-loudspeaker array spaced along a $180^{\circ}$ arc [71]. The study participants identified the source of the sound after each presentation of a pulsed pink noise signal at $70 \mathrm{~dB}$ SPL roved $\pm 3 \mathrm{~dB}$. Twelve of eighteen participants made significantly fewer errors when listening in the bimodal condition than with the HA or implant alone. On average, the bimodal errors were significantly lower than for the implant-only condition.

Seeber and colleagues used an 11-loudspeaker array $\left(100^{\circ}\right.$ arc) to evaluate horizontal plane localization in 11 postlingually deafened adults with bimodal devices [63]. The loudspeakers themselves were hidden from the participants, who indicated the sound source through use of a laser beam that could be placed anywhere along a $140^{\circ}$ arc. Four participants were unable to localize in any of the three tested conditions (HA only, CI only, and bimodal), four were able to localize the sound as being from either the right or left in the bimodal condition, two had some localization ability beyond right/left, and one had good localization ability when using the $\mathrm{CI}$ and $\mathrm{HA}$ in combination. The authors suggest that the participants who were able to localize relied on interaural loudness differences.

Although both localization and speech recognition tasks depend on level and timing cues, how these cues might be used differently for a given subject or how the underlying mechanisms associated with their perception might differ for an individual is unclear. The localization abilities of 12 adults with bimodal devices were investigated with an eight-speaker array ( $108^{\circ}$ arc) from which everyday sounds were presented randomly [58]. Two of the twelve subjects who demonstrated the most consistent binaural benefits for speech recognition in noise (in another part of the study) were disparate in their localization abilities; one had the second highest localization score and the other the worst score.

In conclusion, bimodal listening provided through a $\mathrm{CI}$ in one ear and an HA in the contralateral ear results in significant binaural improvements, including speech recognition in noise, localization, and functional abilities in everyday life. Although these findings in adults are promising, further research is needed to optimize amplification in the nonimplanted ear, both alone and in conjunction with a contralateral CI. In addition, by providing amplification to the nonimplanted ear, the consequences of asymmetrical auditory deprivation that can be created with unilateral cochlear implantation are reduced.

\section{RESTORATION OF SYMMETRICAL HEARING WITH BILATERAL LISTENING: TWO COCHLEAR IMPLANTS}

In this section, we review selected studies of speechrecognition and localization abilities in subjects who receive two CIs (summarized in Appendix 2). In these studies, individuals may have received simultaneous implants (i.e., both ears implanted during the same surgery) or sequential implants (i.e., each ear implanted but with a period of time between the first and second ear surgeries). Of significance is the very large number of potential sequential bilateral CI candidates worldwide. More than 120,000 individuals have received unilateral CIs with one of the three Food and Drug Administrationapproved devices (e.g., Advanced Bionics Corporation, Cochlear Americas, MED-EL Corporation). Of that estimated number, at least 4,600, or 4 percent, have received bilateral CIs; however, the rate of bilateral implantation is rising. In our clinical practice at Washington University, adults with profound hearing loss, including those who have already received one implant, inquire weekly about bilateral implantation.

\section{Speech Recognition: Sequential Implantation}

Bilateral implantation has the potential to improve listening performance in noise and in quiet. A withinsubject comparison of bilateral and unilateral speechrecognition abilities was evaluated in nine adults (six sequential, three simultaneous) tested in three conditions: right implant, left implant, and bilateral implants [72]. Stimuli were monosyllabic words in quiet at $65 \mathrm{~dB}$ SPL and $0^{\circ}$ azimuth and sentences at a $+10 \mathrm{~dB}$ SNR with speech-shaped noise at $\pm 90^{\circ}$. For the majority of subjects, the bilateral score was higher than the best unilateral score. In quiet, the average word-recognition score was 18.7 percentage points higher with two CIs than with one. In noise, the average sentence-recognition score was 31.1 percentage points higher with bilateral implants than with the implanted ear ipsilateral to the noise and 10.7 percentage points higher than with the implanted ear contralateral to the noise. Subjects informally reported consistent use of bilateral implants and improved sound quality (e.g., more natural, fuller, richer) with both implants than with one.

In the same year, these colleagues used similar stimuli and different SNRs in a four-loudspeaker arrangement to evaluate binaural summation and binaural squelch effects in the same bilateral implant recipient group [73]. 
To reduce the head shadow effect, they presented the stimuli in a manner that produced similar SNRs across ears. One list of 20 sentences was presented in quiet and in noise with different SNRs depending on the subject's performance. The gain in SNR at the speech reception threshold (SRT) was calculated. Subjects were tested with bilateral implants and with the better unilateral ear (based on the monosyllabic score in quiet). SRTs in noise resulted in an average $4 \mathrm{~dB}$ SNR gain (standard deviation $1.9 \mathrm{~dB}$ ) in the bilateral compared with the unilateral condition; this gain was attributed to the ability to use binaural processing cues [73]. In this study, most subjects experienced a bilateral benefit shortly after implantation of the second ear.

Sequential implantation in 28 adults with 1 to 7 years between ears resulted in poor performance in the second implanted ear for subjects who had longer periods of time between implanted sides [74]. After 9 months of stimulation in the second ear, scores were poorer in noise in the second ear than the first ear. Compared with the first implanted ear alone, a significant bilateral improvement occurred with speech and noise from the front and when noise was ipsilateral to the first ear. No bilateral advantage occurred when noise was contralateral to the first ear. Preoperative predictors of whether the second ear to be implanted would be the "better" or "poorer" ear did not necessarily agree with postoperative performance in the second ear. This finding is also observed clinically; in other words, predicting performance for a second implanted ear is as difficult as predicting performance for a first implanted ear.

A similar finding, that speech-recognition performance was poorer for the second implanted ear than the first, was reported in a sample of sequentially implanted adults [75]. Among five subjects, three were adults with postlingual deafness. The other two were teenagers with congenital hearing loss who were implanted at ages 8 and 11 in the first ear and age 12 in the second ear. Sentences were presented in quiet and noise, with speech from the front and Comité Consultatif International Téléphonique et Télégraphique (CCITT) (International Telephone and Telegraph Consultative Committee) noise at either the front or $\pm 90^{\circ}$. The bilateral implant condition was significantly better than the unilateral implant conditions, mainly as a result of the head shadow effect. With a mean 1.5 years of bilateral use, the second implanted ear remained poorer than the first implanted ear for three of the five subjects for sentence-recognition scores when noise was presented ipsilateral to either the first or sec- ond implanted ear and for two of five subjects for sentences presented in quiet to either the first or second implanted ear. The authors suggested that systematic deprivation effects as a result of reduced acoustic input to the second ear may account for the poorer performance for some patients. An alternative explanation is that the second ear may need more time to acclimate to electrical stimulation.

Although duration of deafness has been reported to correlate with unilateral implant outcomes, complex interactions between ears may obscure such relations with bilateral implantation. Sequential bilateral CI recipients participated in an investigation of bilateral CI use with an adaptive SRT procedure in an anechoic chamber [76]. Noise was constructed to match the long-term spectrum of the sentence stimuli and presented at a fixed level. For the 18 subjects for whom the SRT could be measured in all conditions, mean improvements binaurally were $6.8 \mathrm{~dB}$ because of the head shadow effect, $2.1 \mathrm{~dB}$ because of binaural summation effects, and $0.9 \mathrm{~dB}$ because of binaural squelch effects (only for noise on the left). The authors reported no correlation between head shadow, binaural loudness summation, or binaural squelch results and duration of deafness of either ear or the average duration of deafness across ears, expressed in either absolute values or as a fraction of age.

Many adults recall the length of time and effort needed to learn to perceive speech in the first implanted ear and are anxious to know what to expect for the second implanted ear. The clinical questions of expected outcomes in the second implanted ear and time required to reach asymptotic performance are unanswered. To address these questions, background information and preliminary data are shown in the Table and Figure $\mathbf{4}$ for four adult patients who had symmetrical hearing histories and received sequential implants 5 years apart at Washington University School of Medicine [77]. For each subject, the severity of hearing loss, aided detection levels, and speech recognition scores before implantation were symmetrical. The age at onset for both initial hearing loss and profound hearing loss was similar between the right and left ears for each subject.

In Figure 4, speech-recognition scores for CNC words in quiet and HINT sentences in noise for individual subjects are shown. Test materials were presented at $60 \mathrm{~dB}$ SPL; speech-spectrum noise was from the front at a +8 SNR. Statistically significant differences were determined with a binomial model at the 0.05 level. For each subject, speech-recognition scores in the second implanted 
Table.

Background information for four subjects who received sequential cochlear implants (CIs).

\begin{tabular}{|c|c|c|c|c|c|c|c|c|c|}
\hline Subject & Ear & $\begin{array}{c}\text { AAO } \\
\text { HL }\end{array}$ & $\begin{array}{l}\text { AAO } \\
\text { SPHL }\end{array}$ & PTA & $\begin{array}{l}\text { Aided } \\
\text { PTA }\end{array}$ & $\begin{array}{c}\text { Pre-I } \\
\text { HINTQ (\%) }\end{array}$ & $\begin{array}{c}\text { Pre-I } \\
\text { CNC (\%) }\end{array}$ & AAI & $\begin{array}{c}\text { CI } \\
\text { Device }\end{array}$ \\
\hline \multirow[t]{2}{*}{ S1 } & Right $^{*}$ & 14 & 42 & 105 & 58 & 0 & 0 & 47 & AB C1 \\
\hline & Left & 14 & 42 & 107 & 58 & 0 & 0 & 52 & AB $90 \mathrm{~K}$ \\
\hline & Left & 5 & 61 & 80 & 46 & 32 & 4 & 64 & N 24RE \\
\hline \multirow[t]{2}{*}{ S3 } & Right & 50 & 56 & 110 & 65 & 0 & 0 & 76 & N 24RE \\
\hline & Left $^{*}$ & 50 & 58 & 88 & 60 & 18 & 0 & 71 & N 24R \\
\hline & Left $^{*}$ & 5 & 5 & 103 & 58 & 46 & 4 & 38 & N 24M \\
\hline
\end{tabular}

*First implanted ear.

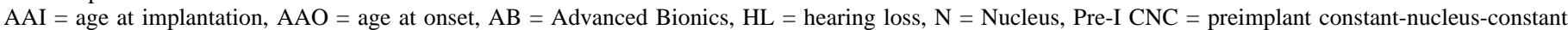
words in quiet, Pre-I HINTQ = preimplant Hearing in Noise Test sentences in quiet, PTA = pure tone average, SPHL = severe-to-profound hearing loss.

ear (filled symbols, solid lines) were higher faster (at earlier intervals) and remained higher than the same interval for the first implanted ear (open symbols, dashed lines). Because the ears were nearly identical for each subject (symmetrical hearing levels, similar speech-recognition scores, similar length of deafness between ears before implantation) and across subjects (5 years between implants for all subjects), the difference in scores between the first and second implanted ears is attributed to the experience of hearing with the first implant. Subject 4 had the largest difference between the first and second implanted ears and this difference continued through the 12-month interval. Although subject 4 had a symmetrical hearing history, the hearing loss was profound in both ears at an early age (5 years), whereas the other three subjects did not have severe-to-profound hearing loss until adulthood. Longitudinal studies with a larger sample size will help address questions of sequential implantation, including factors that contribute to bilateral performance and rate of progress in the second implanted ear.

\section{Speech Recognition: Simultaneous Implantation}

Fewer studies of bilateral benefit have been conducted with adults who received simultaneous implants. The earliest report included nine subjects after 3 months of Nucleus implant use [78]. CNC words, CUNY sentences, and/or HINT sentences were presented in quiet and CUNY sentences were presented from the front in noise $\left( \pm 90^{\circ}\right)$ at individual SNRs. After 3 months of bilateral use in quiet, a significant bilateral improvement was reported over the better ear in five subjects for CUNY sentences and two subjects for CNC words. Four of nine subjects showed a significant bilateral improvement over the better ear when listening to speech and noise from the

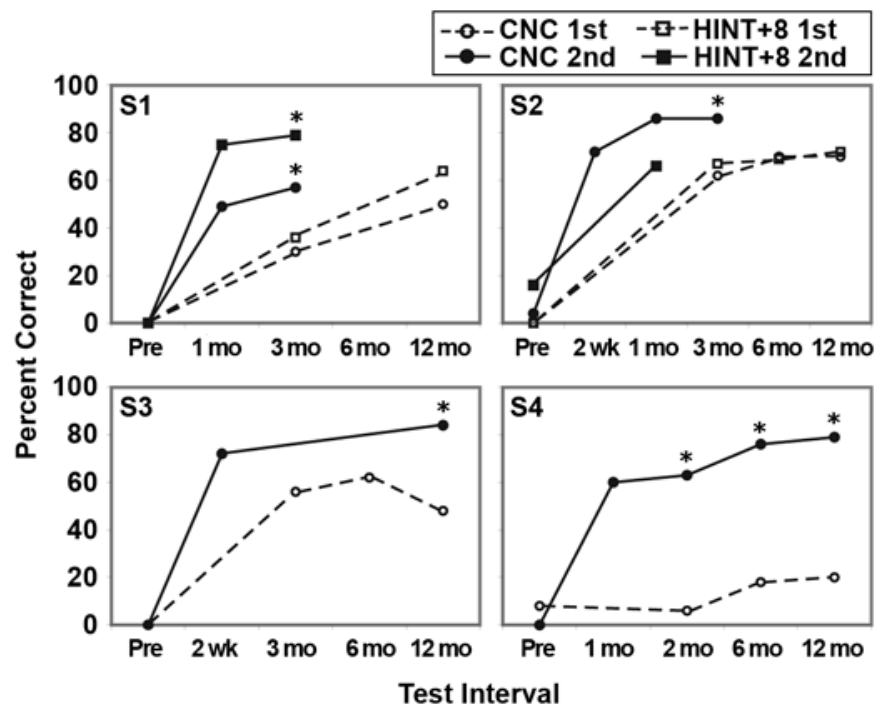

Figure 4.

Individual subjects' speech-recognition scores for consonant-nucleusconsonant (CNC) words (circle symbols) and Hearing in Noise Test sentences in noise and $+8 \mathrm{~dB}$ signal-to-noise ratio (HINT+8) (square symbols). Scores for first implanted ear over time are displayed with dashed lines and open symbols, and those for second implanted ear with solid lines and closed symbols. ${ }^{*}$ Significant differences $(p<$ 0.05 ) between first and second ear performance on specific measure at same test interval.

front. Adding the contralateral ear (opposite the noise source) resulted in a significant binaural improvement in scores for seven tested subjects. When adding the ear ipsilateral to the noise, only one of seven (noise-right condition) and three of seven (noise-left condition) showed binaural improvement. The largest improvements were related to the head shadow effect. Further assessment of these subjects at 1 year postimplantation resulted in similar conclusions [79]. 
In most studies of bilateral implantation, a single noise source is used to determine binaural effects. In everyday communication, a listener may face the speaker but have multiple noise sources in the surroundings. Additionally, the use of multiple noise sources reduces the impact of the head shadow effect and therefore bilateral advantages may primarily result from binaural summation and squelch effects. Speech recognition in noise with multiple noise sources was evaluated in 16 bilaterally implanted adults, 14 of whom were simultaneously implanted [80]. In bilateral and unilateral conditions, participants responded to both a fixed (+10 SNR on the Connected Speech Test [CST]) and an adaptive SNR task with HINT sentences. The bilateral condition was significantly better than the best unilateral condition by $3.3 \mathrm{~dB}$ for the adaptive measure and 9 percentage points for the CST. The placement of the speech and noise stimuli in the study suggests that the improved scores in noise result from binaural processes (e.g., summation and squelch) rather than the head shadow effect.

Recently, the results of two separate longitudinal, multicenter U.S. clinical studies in bilateral implantation have become available. One study included 37 adults with simultaneous Nucleus 24 Contour implants assessed at 1,3 , and 6 months postactivation [81]. Speech recognition in quiet was evaluated with CNC words and HINT sentences and in noise with the Bench, Kowal, Bamford Speech in Noise test [82] with speech in the front and noise from the front, right, or left. At the 3-month postimplant interval, subjects wore only one speech processor for 3 weeks and then returned to wearing both implants. Bilateral scores were significantly higher than unilateral scores at 6 months postimplant. Improvement in scores in the bilateral condition was primarily attributed to head shadow effects, with binaural squelch and binaural redundancy effects noted for only a few subjects and to a lesser extent. In this study, the Abbreviated Profile of Hearing Aid Benefit (APHAB) questionnaire was administered after the 3-week period with unilateral implant use and then again after bilateral wear at the 6-month postimplant interval. Subject responses on three of the four subscales of the APHAB (ease of communication, reverberant listening, and background noise) indicated a strong preference for bilateral implants.

In the second multicenter study of simultaneous implantation in adults, 26 patients received MED-EL Combi 40+ implants [83]. The measures were CNC words in quiet and CUNY sentences in noise with speech from the front and noise (CCITT) from the front, right, or left $\left( \pm 90^{\circ}\right)$. Data collection occurred at $1,3,6$, and 12 months postactivation. Unique to this study was the presentation of stimuli to each subject with direct audio input (DAI) via the speech processor to address the issue of test environment inconsistencies across centers. DAI also bypasses the compression circuitry of the speech processor. Head shadow and binaural summation effects were reported at 6 and 12 months postimplant. Notably, binaural squelch effects were significant but not evident until 1 year of implant use, suggesting that this binaural advantage may require more experience with bilateral input.

In summary, whether implanted with simultaneous or sequential procedures, the largest and most consistent benefit in adults is the head shadow effect, followed by the binaural summation, and lastly binaural squelch effects. The relative size of these effects is not dissimilar from normal-hearing listeners, the largest effect being the head shadow effect, followed by the binaural summation and squelch effects. Results across speech-recognition studies with CI recipients vary because of factors such as type of speech materials and noise, SNR, location of noise, and fixed-level versus adaptive SNRs. Variability in speech recognition is present among subjects and between implanted sides for individual subjects. For sequentially implanted ears, finding a suitable test material that does not result in ceiling effects for the first implanted (more experienced) ear and floor effects for the second implanted ear (less experienced) can be a challenge. If either condition exists, a bilateral improvement may not be evident.

\section{Localization}

Several studies address whether sound localization is improved when patients have bilateral CIs compared with one device. In general and compared with unilateral implant conditions, adult recipients of bilateral implants perform fairly well in localization tasks in the horizontal plane $[75,78,84-93]$. For example, in five subjects using pink noise bursts presented from eight loudspeakers that spanned $108^{\circ}$, unilateral conditions resulted in $20^{\circ}$ to $60^{\circ}$ RMS errors, but only $10^{\circ}$ RMS errors were noted for bilateral conditions [93]. The variability in responses also substantially decreased in the bilateral compared with unilateral conditions, suggesting that subjects were more consistent in their judgments during the localization task when both implants were worn. Nopp and colleagues assessed localization in the frontal horizontal plane by using nine loudspeakers and speech-shaped noise bursts 
in an anechoic chamber [88]. In a sample of 20 adults, the mean improvement in the bilateral condition was $30^{\circ}$ with a decrease in variability of $>16^{\circ}$, again suggesting more consistent decision-making during the task. Neuman et al. investigated whether stimulus type affects sound localization by comparing performance between a speech stimulus (1.1 s duration sentence) and pink noise (2-500 ms bursts) presented across a nine-speaker array with each speaker placed $22.5^{\circ}$ apart [87]. All stimuli were presented in a quiet classroom. In eight adults simultaneously implanted with Nucleus 24 CIs, mean RMS errors were $29.0^{\circ}$ for bilateral conditions and $54.0^{\circ}$ and $46.5^{\circ}$ for unilateral left and right conditions, respectively. Performance was similar for speech and pink noise bursts. Laszig et al. used shortened sentence stimuli and a 12-speaker array forming a circle around the subject [85]. In the unilateral condition, subjects responded toward the side of stimulation, and 15 of 16 subjects who participated in this study had better localization with bilateral device use.

Although improved, localization abilities of bilateral implant recipients appear to be considerably poorer than individuals with normal hearing or those with less severe hearing loss. For example, performance on a horizontal localization task was on average $2^{\circ}$ in normal-hearing participants and $10^{\circ}$ in HA users [94]. Under similar test conditions, 20 participants with bilateral implants had errors of $24^{\circ}$ but a significant improvement over the unilateral condition of $67^{\circ}$ (chance $=65^{\circ}$ ). In another study, results between normal-hearing controls who were agematched with bilateral implant patients were compared on a task of MAA levels assessed in the horizontal plane with use of white noise bursts [75]. Spatial discrimination was good when the reference point was in the front or back of the head, and MAA values in bilateral implant subjects were comparable with normals (controls $=1^{\circ}-4^{\circ}$, patients $=3^{\circ}-8^{\circ}$ ). Performance was much poorer, however, when the reference point was on the sides (controls $=7^{\circ}-10^{\circ}$, patients $=30^{\circ}-45^{\circ}+$ ). Compared with normal controls, just noticeable difference values for bilateral implant subjects were similar for ILDs but substantially poorer for ITDs. In other psychophysical studies, ILD thresholds were reported to be similar to those of normalhearing subjects [75,93,95].

While studies show consistently good sensitivity for ILDs, sensitivity is poor for ITDs [75,90-93,96-97]. For example, the effect of varied ITDs and ILDs using electrical pulse trains was evaluated in five bilateral implant subjects [93]. Sensitivity to ILD cues for some subjects was better than $1 \mathrm{~dB}$. ITD sensitivity was moderate, generally about $100 \mu$ s and reduced quickly when the stimulation rate for unmodulated pulse trains was increased beyond a few hundred hertz. In another study, stimuli were 200 ms Gaussian noise bursts presented acoustically and delivered via headphones that fit over the implant devices [98]. ITD and ILD discrimination tasks consisted of a two-interval forced-choice adaptive procedure that determined whether the sounds were perceived as moving from right-to-left or left-to-right. ILD thresholds were good; mean thresholds were 3.8 and $1.9 \mathrm{~dB}$ with and without compression activated in the speech processor, respectively. ITD thresholds were poor; 5 of 11 tested subjects had thresholds of $<1,000 \mu$ s and the remainder $>1,000 \mu \mathrm{s}$. In this study, the manner of stimulus delivery (via headphones) allowed comparison of ITD and ILD thresholds with a measure of localization using the same listening condition and stimuli. When two outlying participants were omitted, ILD thresholds were highly correlated with sound localization scores.

ILD cues are thought to be the primary cue for localization for bilateral implant subjects; however, ITDs may still play a role $[89,92,99]$. Depending on the speaker array, low-rate ITD cues in the envelope may assist in sound localization when ILD cues become ambiguous [92]. Alternate coding strategies that attempt to preserve fine structure may allow more salience of ITD cues. Although envelope information is maintained in today's speech-coding strategies, those strategies that support finestructure information may prove more useful, especially for bilateral patients. A new coding strategy designed to better preserve timing cues, referred to as "peak derived timing” (PDT) was implemented and described by van Hoesel and colleagues [93]. PDT aims to extract the timing information within each frequency band rather than only from the envelope of respective bands. SRTs for sentences were improved in noise for four bilaterally implanted subjects using PDT programmed on research processors where loudness was adjusted in the bilateral condition to account for binaural summation effects [93]. A significant binaural squelch effect of 1 to $2 \mathrm{~dB}$ was also reported.

Few studies have evaluated longitudinal changes in localization in adult bilateral recipients. Grantham and colleagues investigated the ability of 22 bilaterally implanted adults to localize noise and speech signals in the horizontal plane [84]. In a subset of 12 subjects, 
longitudinal changes in localization at 5 and 15 months after bilateral implant use were also assessed. Testing in the unilateral and bilateral conditions used 43 speakers $\left( \pm 90^{\circ}\right), 17$ of which were active. A $200 \mathrm{~ms}$ speech signal or noise burst was presented. Results are reported as adjusted constant error values $(\hat{\mathrm{C}})$, where $50.5^{\circ}$ represents chance. In normal hearing participants, $C$ ranged from $3.5^{\circ}$ to $7.8^{\circ}\left(\right.$ mean $\left.=5.6^{\circ}\right)$. With bilateral implants, C varied from $8.1^{\circ}$ to $43.4^{\circ}$ (mean $\left.=24.1^{\circ}\right)$. With unilateral implants, $\hat{C}$ was near chance for all subjects. Only 2 of 12 subjects showed substantial improvement between the 5- and 15-month postintervals.

Age at onset of profound hearing loss may be a critical factor in the ability to localize sound. In some reports, individuals with congenital or early childhood deafness who received bilateral implants as adults perform the poorest on localization tasks. For example, in Nopp and colleagues' 2004 study [88], all but 2 of 20 subjects showed improvements in the bilateral compared with unilateral condition. The two subjects who did not show bilateral improvement had onset of profound hearing loss before age 6 . In the Neuman et al. study of localization [87], one of eight subjects had congenital hearing loss, rather than postlingual onset, and had the poorest bilateral RMS error score but not the poorest unilateral score. As more data are acquired in children with profound hearing loss who receive bilateral implants at various ages, a critical period for acquiring binaural hearing abilities, including localization, may be defined.

Results across localization studies vary as a result of several factors. The angular separation between speakers can affect RMS error [92]. Localization performance can be poorer at higher stimulus inputs (70 versus $60 \mathrm{~dB}$ SPL) because of distortion of ILD cues from activation of the automatic gain controls in clinical speech processors [93]. Directional versus omnidirectional microphones and microphone placement may affect stimulus level depending on the direction of the sound source. As with speech recognition, localization ability varies among subjects and between implanted sides for individual subjects. Although results do not appear to be device or codingstrategy specific at this time, this could change with the implementation of new processing or better bilateral device fitting in the future.

\section{Fitting of Bilateral Implants}

A previous question in the field was whether a unilateral CI recipient might benefit equally well from the fit- ting of bilateral microphones coupled to one implant, rather than undergoing bilateral CI surgeries. For CI recipients using a dual microphone at each ear coupled to a single CI system, speech-recognition performance has been shown to be poorer than with bilateral implants $[74,94,100]$. Bilateral microphones with a single implant, therefore, do not achieve the binaural processing capabilities that may be afforded by bilateral implants.

Optimal techniques for fitting of bilateral implants are currently unknown. At the present time, clinical practice is to program each CI separately, followed by adjustments when both speech processors are activated together. Lawson and colleagues experimented with a single speech processor with one microphone input coupled to bilateral implants (Nucleus 22) in order to add channels to create more effective stimulation between ears [95]. In one subject, pitch-matching and pitch-ranking procedures were completed in order to identify bilateral pairs of electrodes with similar pitch percepts. With each of three pitch-matched pairs and when stimulus pulses were matched in loudness, the subject could determine the ear that received the earlier onset for interaural delays as short as $150 \mu \mathrm{s}$. In another single-subject study, ITD sensitivity was investigated in a recipient of a six-electrode Ineraid device in one ear and an eight-electrode Clarion device in the other [99]. ITDs were improved when pitch matching was used to select electrode pairs, and electrodes that had good ITD sensitivity had the greatest ILD sensitivity. Electrodes with similar pitches were more likely to result in good ITD sensitivity. The relative position of the two electrode arrays as determined by the pitch matches compared closely with the estimates of the relative position of the arrays in the cochlea from computed tomography scans. Further research on the optimization of stimulus parameters such as electrode pairing, stimulus timing, and stimulus level between ears might further extend binaural improvements for patients [9293,97].

Sensitivity to meaningful binaural cues has been demonstrated for an individual with bilateral implants of differing types [99]. This finding is encouraging since a substantial number of patients will likely have different implant types in each ear, depending on the time of implantation of the first ear and the length of time that has occurred between sequential devices. Additional reports exist of patients using very different implant types in the two ears, particularly patients who were implanted with early technology [101-102]. For example, 
two patients received a MED-EL CIS-Link processor and internal Ineraid device in one ear and, subsequently, a Clarion HiFocus implant in the other ear [103]. One patient had significantly improved bilateral scores for CNC words and HINT sentences in quiet at $70 \mathrm{~dB}$ SPL. The other patient had mixed results; some tests showed no bilateral benefit (CNC words), some a small benefit (vowel identification), and others a significant increase (HINT sentences in noise at a +5 SNR). In Tyler et al. [102], three of seven sequentially implanted subjects had different devices in each ear but still showed bilateral benefit. Although different processing strategies and devices between ears may introduce variability, similar variability can exist between ears when two identical devices are worn.

The effects of converting bilateral implant recipients to a strategy with increased rate and number of channels was investigated in seven adults who received simultaneous bilateral Advanced Bionics CII HiFocus CIs [104]. Recipients had used an eight-channel continuous interleaved sampling (CIS) strategy with 813 pps for more than 18 months. Following an ABABAB design, patients alternated high resolution (HiRes) paired stimulation (16 channels, 5,156 pps) with HiRes sequential stimulation (16 channels, 2,900 pps) for 1 month. Bilateral speech recognition scores were evaluated with CUNY sentences in multitalker speech babble noise at individually determined SNRs, speech and noise both from the front. HiRes scores improved by 30 to 60 percentage points in 1 month for six of seven subjects compared with CIS scores. Four of five subjects maintained improvements after 6 months of use. Unclear is whether improvements were associated with an increase in channel number, an increase in rate of stimulation, or both.

In conclusion, binaural advantages are observed in adult bilateral CI recipients, the greatest effects being the head shadow effect and improvements in localization, followed by loudness summation; the least benefit is the squelch effect. These improvements occur despite relatively poor temporal processing, as noted in ITD studies. The benefits of bilateral implants and the desire to wear two devices are reported by patients both anecdotally and in some questionnaire data [72,81,105]. For example, patients report decreased effort in communicating throughout the day and less time spent strategizing about where to place themselves in order to hear.

\section{SUMMARY AND CONCLUSIONS}

Bilateral hearing loss causes changes to the central auditory system and processes needed for binaural integration are disrupted. When individuals with hearing loss have asymmetrical input, binaural processing is more disrupted than when the input is symmetrical. Asymmetrical hearing can result from asymmetry in unaided thresholds and can also be created by either unilateral amplification or unilateral cochlear implantation in patients with bilateral hearing loss. Results from bilateral CI recipients, traditional bimodal recipients, and nontraditional bimodal recipients indicate substantial bilateral benefits that include improvements in speech recognition in noise, localization, and functional everyday communication. Bilateral stimulation of the auditory system and, to the extent possible, symmetrical hearing via two CIs or one CI combined with an HA are highly encouraged for all patients.

\section{ACKNOWLEDGMENTS}

We wish to acknowledge Laura Holden, Dawn Koch, Lisa Potts, and Rosalie Uchanski, as well as two anonymous reviewers, for helpful comments on an earlier version of the article.

This material was based on work supported in part by the National Institute on Deafness and Communication Sciences, National Institutes of Health (grants R01DC00581 and K23DC00514).

The authors have declared that no competing interests exist.

\section{REFERENCES}

1. Brown KD, Balkany TJ. Benefits of bilateral cochlear implantation: A review. Curr Opin Otolaryngol Head Neck Surg. 2007;15(5):315-18. [PMID: 17823546]

2. Ching TY, Van Wanrooy E, Dillon H. Binaural-bimodal fitting or bilateral implantation for managing severe to profound deafness: A review. Trends Amplif. 2007;11(3): 161-92. [PMID: 17709573]

3. Schafer EC, Amlani AM, Seibold A, Shattuck PL. A meta-analytic comparison of binaural benefits between bilateral cochlear implants and bimodal stimulation. J Am Acad Audiol. 2007;18(9):760-76. [PMID: 18354885] 
4. Tyler RS, Dunn CC, Witt SA, Preece JP. Update on bilateral cochlear implantation. Curr Opin Otolaryngol Head Neck Surg. 2003;11(5):388-93. [PMID: 14502072]

5. Durlach NJ, Colburne HS. Binaural phenomena. In: Carterette EC, Friedman MP, editors, Handbook of perception. San Diego (CA): Academic Press; 1978. p. 373-406.

6. Marks LE. Binaural summation of the loudness of pure tones. J Acoust Soc Am. 1978;64(1):107-13. [PMID: 711989]

7. Haggard MP, Hall JW. Forms of binaural summation and the implications of individual variability for binaural hearing aids. Scand Audiol Suppl. 1982;15:47-63. [PMID: 6287568]

8. Bronkhorst AW, Plomp R. The effect of head-induced interaural time and level differences on speech intelligibility in noise. J Acoust Soc Am. 1988;83(4):1508-16. [PMID: 3372866]

9. Plomp R, Mimpen AM. Effect of the orientation of the speaker's head and the azimuth of a noise source on the speech reception threshold for sentences. Acustica. 1981; 8:325-28.

10. Levitt H, Rabiner LR. Binaural release from masking for speech and gain in intelligibility. J Acoust Soc Am. 1967; 42(3):601-8. [PMID: 6073973]

11. Yost WA, Dye RH Jr. Discrimination of interaural differences of level as a function of frequency. J Acoust Soc Am. 1988;83(5):1846-51. [PMID: 3403800]

12. Kiang NY, Liberman MC, Levine RA. Auditory-nerve activity in cats exposed to ototoxic drugs and high-intensity sounds. Ann Otol Rhinol Laryngol. 1976;85(6 Pt 1): 752-68. [PMID: 999140]

13. Leake PA, Hradek GT. Cochlear pathology of long term neomycin induced deafness in cats. Hear Res. 1988;33(1): 11-33. [PMID: 3372368$]$

14. Moore JK, Niparko JK, Perazzo LM, Miller MR, Linthicum FH. Effect of adult-onset deafness on the human central auditory system. Ann Otol Rhinol Laryngol. 1997; 106(5):385-90. [PMID: 9153102]

15. Born DE, Rubel EW. Afferent influences on brain stem auditory nuclei of the chicken: Neuron number and size following cochlea removal. J Comp Neurol. 1985;231(4): 435-45. [PMID: 3968247]

16. Trune DR. Influence of neonatal cochlear removal on the development of mouse cochlear nucleus: I. Number, size, and density of its neurons. J Comp Neurol. 1982;209(4): 409-24. [PMID: 7130465]

17. Webster DB. A critical period during postnatal auditory development of mice. Int J Pediatr Otorhinolaryngol. 1983;6(2):107-18. [PMID: 6662618]

18. Ryugo DK, Pongstaporn T, Huchton DM, Niparko JK. Ultrastructural analysis of primary endings in deaf white cats: Morphologic alterations in endbulbs of Held. J Comp Neurol. 1997;385(2):230-44. [PMID: 9268125]
19. Ryugo DK, Rosenbaum BT, Kim PJ, Niparko JK, Saada AA. Single unit recordings in the auditory nerve of congenitally deaf white cats: Morphological correlates in the cochlea and cochlear nucleus. J Comp Neurol. 1998;397(4): 532-48. [PMID: 9699914$]$

20. Lee DJ, Cahill HB, Ryugo DK. Effects of congenital deafness in the cochlear nuclei of Shaker-2 mice: An ultrastructural analysis of synapse morphology in the enbulbs of Held. J Neurocytol. 2003;32(3):229-43. [PMID: 14724386]

21. Redd EE, Pongstaporn T, Ryugo DK. The effects of congenital deafness on auditory nerve synapses and globular bushy cells in cats. Hear Res. 2000;147(1-2):160-74. [PMID: 10962182]

22. Silverman MS, Clopton BM. Plasticity of binaural interaction. I. Effect of early auditory deprivation. J Neurophysiol. 1977;40(6):1266-74. [PMID: 925728]

23. Killackey HP, Ryugo DK. Effects of neonatal peripheral auditory system damage on the structure of the inferior colliculus of the rat. Anat Rec. 1977;187:624.

24. Robertson D, Irvine DR. Plasticity of frequency organization in auditory cortex of guinea pigs with partial unilateral deafness. J Comp Neurol. 1989;282(3):456-71.

[PMID: 2715393]

25. Rajan R, Irvine DR, Wise LZ, Heil P. Effect of unilateral partial cochlear lesions in adult cats on the representation of lesioned and unlesioned cochleas in primary auditory cortex. J Comp Neurol. 1993;338(1):17-49.

[PMID: 8300898$]$

26. Moore BC, Glasberg BR. Frequency discrimination of complex tones with overlapping and non-overlapping harmonics. J Acoust Soc Am. 1990;87(5):2163-77. [PMID: 2348021]

27. Clopton BM, Silverman MS. Plasticity of binaural interaction. II. Critical period and changes in midline response. J Neurophysiol. 1977;40(6):1275-80. [PMID: 925729]

28. Hubel DH, Wiesel TN. Binocular interaction in striate cortex of kittens reared with artificial squint. J Neurophysiol. 1965;28(6):1041-59. [PMID: 5883731]

29. Wiesel TN. Postnatal development of the visual cortex and the influence of environment. Nature. 1982;299(5884): 583-91. [PMID: 6811951]

30. Deitch JS, Rubel EW. Afferent influences on brain stem auditory nuclei of the chicken: Time course and specificity of dendritic atrophy following deafferentation. J Comp Neurol. 1984;229(1):66-79. [PMID: 6490976]

31. Hartmann R, Kral A. Central responses to electrical stimulation. In: Zeng FG, Popper AN, Fay RR, editors. Cochlear implants: Auditory prostheses and electric hearing. New York (NY): Springer; 2004. p. 213-85.

32. Moore DR. Effects of early auditory experience on development of binaural pathways in the brain. Semin Perinatol. 1990;14(4):294-98. [PMID: 2237459] 
33. Knudsen EI. Experience shapes sound localization and auditory unit response properties during development in the barn owl. In: Edelman GM, Gall WE, Cowan WM, editors. Auditory function: Neurobiological bases of hearing. New York (NY): Wiley; 1988. p. 137-49.

34. Rubel EW, Hyson RL, Durham D. Afferent regulation of neurons in the brain stem auditory system. J Neurobiol. 1990;21(1):169-96. [PMID: 2181062]

35. King AJ, Moore DR. Plasticity of auditory maps in the brain. Trends Neurosci. 1991;14(1):31-37. [PMID: 1709531]

36. Baker FH, Grigg P, Von Noorden GK. Effects of visual deprivation and strabismus on the response of neuron in the visual cortex of the monkey, including studies on the striate and prestriate cortex in the normal animal. Brain Res. 1974;66:185-208.

37. Wiesel TN, Hubel DH. Single-cell responses in striate cortex of kittens deprived of vision in one eye. J Neurophysiol. 1963;26:1003-17. [PMID: 14084161]

38. Noble W, Gatehouse S. Interaural asymmetry of hearing loss, Speech, Spatial and Qualities of Hearing Scale (SSQ) disabilities, and handicap. Int J Audiol. 2004; 43(2): 100-14. [PMID: 15035562]

39. Chung SM, Stephens SD. Factors influencing binaural hearing aid use. Br J Audiol. 1986;20(2):129-40. [PMID: 3719161]

40. Swan IR, Gatehouse S. Factors influencing consultation for management of hearing disability. Br J Audiol. 1990; 24(3):155-60. [PMID: 2364186]

41. Pittman AL, Stelmachowicz PG. Hearing loss in children and adults: Audiometric configuration, asymmetry, and progression. Ear Hear. 2003;24(3):198-205. [PMID: 12799541]

42. Gatehouse S, Noble W. The Speech, Spatial and Qualities of Hearing Scale (SSQ). Int J Audiol. 2004;43(2):85-99. [PMID: 15035561]

43. Silman S, Gelfand SA, Silverman CA. Late-onset auditory deprivation: Effects of monaural versus binaural hearing aids. J Acoust Soc Am. 1984;76(5):1357-62. [PMID: 6512097]

44. Gelfand SA, Silman S, Ross L. Long-term effects of monaural, binaural and no amplification in subjects with bilateral hearing loss. Scand Audiol. 1987;16(4):201-7. [PMID: 3438702]

45. Gatehouse S. Apparent auditory deprivation effects of late onset: The role of presentation level. J Acoust Soc Am. 1989;86(6):2103-6. [PMID: 2600300]

46. Hood JD. Speech discrimination in bilateral and unilateral hearing loss due to Ménière's disease. Br J Audiol. 1984;18(3):173-77. [PMID: 6487852]

47. Gelfand SA, Silman S. Apparent auditory deprivation in children: Implications of monaural versus binaural ampli- fication. J Am Acad Audiol. 1993;4(5):313-18. [PMID: 8219298]

48. Hattori H. Ear dominance for nonsense-syllable recognition ability in sensorineural hearing-impaired children: Monaural versus binaural amplification. J Am Acad Audiol. 1993;4(5):319-30. [PMID: 8219299]

49. Arlinger S, Gatehouse S, Bentler RA, Byrne D, Cox RM, Dirks DD, Humes L, Neuman A, Ponton C, Robinson K, Silman S, Summerfield AQ, Turner CW, Tyler RS, Willott JF. Report of the Eriksholm Workshop on Auditory Deprivation and Acclimatization. Ear Hear. 1996;17(3 Suppl): 87S-98S. [PMID: 8807279]

50. Gatehouse S. The time course and magnitude of perceptual acclimatization to frequency responses: Evidence from monaural fitting of hearing aids. J Acoust Soc Am. 1992 Sep;92(3):1258-68. [PMID: 1401514]

51. Silverman CA, Silman S. Apparent auditory deprivation from monaural amplification and recovery with binaural amplification: Two case studies. J Am Acad Audiol. 1990; 1(4):175-80. [PMID: 2132601]

52. Gelfand SA. Long-term recovery and no recovery from the auditory deprivation effect with binaural amplification: Six cases. J Am Acad Audiol. 1995;6(2):141-49. [PMID: 7772783]

53. Harford E. Bilateral cros. Two sided listening with one hearing aid. Arch Otolaryngol. 1966;84(4):426-32. [PMID: 5921720]

54. Shallop JK, Arndt PL, Turnacliff KA. Expanded indications for cochlear implantation: Perceptual results in seven adults with residual hearing. J Speech Lang Pathol Audiol. 1992;16:141-48.

55. Waltzman SB, Cohen NL, Shapiro WH. Sensory aids in conjunction with cochlear implants. Am J Otol. 1992; 13(4):308-12. [PMID: 1415491]

56. Ching TY, Hill M, Brew J, Incerti P, Priolo S, Rushbrook E, Forsythe L. The effect of auditory experience on speech perception, localization, and functional performance of children who use a cochlear implant and a hearing aid in opposite ears. Int J Audiol. 2005;44(12):677-90. [PMID: 16450919]

57. Ching TY, Incerti P, Hill M. Binaural benefits for adults who use hearing aids and cochlear implants in opposite ears. Ear Hear. 2004;25(1):9-21. [PMID: 14770014]

58. Dunn CC, Tyler RS, Witt SA. Benefit of wearing a hearing aid on the unimplanted ear in adult users of a cochlear implant. J Speech Lang Hear Res. 2005;48(3):668-80. [PMID: 16197280]

59. Hamzavi J, Pok SM, Gstoettner W, Baumgartner WD. Speech perception with a cochlear implant used in conjunction with a hearing aid in the opposite ear. Int $\mathrm{J}$ Audiol. 2004;43(2):61-65. [PMID: 15035557]

60. Kong YY, Stickney GS, Zeng FG. Speech and melody recognition in binaurally combined acoustic and electric 
hearing. J Acoust Soc Am. 2005;117(3 Pt 1):1351-61. [PMID: 15807023]

61. Morera C, Manrique M, Ramos A, Garcia-Ibanez L, Cavalle L, Huarte A, Castillo C, Estrada E. Advantages of binaural hearing provided through bimodal stimulation via a cochlear implant and a conventional hearing aid: A 6-month comparative study. Acta Otolaryngol. 2005;125(6): 596-606. [PMID: 16076708]

62. Mok M, Grayden D, Dowell RC, Lawrence D. Speech perception for adults who use hearing aids in conjunction with cochlear implants in opposite ears. J Speech Lang Hear Res. 2006;49(2):338-51. [PMID: 16671848]

63. Seeber BU, Baumann U, Fastl H. Localization ability with bimodal hearing aids and bilateral cochlear implants. J Acoust Soc Am. 2004;116(3):1698-1709. [PMID: 15478437]

64. Tyler RS, Parkinson AJ, Wilson BS, Witt S, Preece JP, Noble W. Patients utilizing a hearing aid and a cochlear implant: Speech perception and localization. Ear Hear. 2002;23(2):98-105. [PMID: 11951854$]$

65. Blamey PJ, Dooley GJ, James CJ, Parisi ES. Monaural and binaural loudness measures in cochlear implant users with contralateral residual hearing. Ear Hear. 2000;21(1): 6-17. [PMID: 10708069]

66. Potts LG. Recognition and localization of speech by adult cochlear implant recipients wearing a digital hearing aid in the non-implanted ear (bimodal hearing) [thesis]. St. Louis (MO): Washington University School of Medicine; 2006.

67. Skinner MW, Holden LK, Holden TA, Demorest ME. Comparison of procedures for obtaining thresholds and maximum acceptable loudness levels with the Nucleus cochlear implant system. J Speech Hear Res. 1995;38(3): 677-89. [PMID: 7674659]

68. Skinner MW, Holden LK, Whitford LA, Plant KL, Psarros C, Holden TA. Speech recognition with the nucleus 24 SPEAK, ACE, and CIS speech coding strategies in newly implanted adults. Ear Hear. 2002;23(3):207-23.

[PMID: 12072613]

69. Skinner MW. Optimizing cochlear implant speech performance. Ann Otol Rhinol Laryngol Suppl. 2003;191:4-13. [PMID: 14533838]

70. Armstrong M, Pegg P, James C, Blamey P. Speech perception in noise with implant and hearing aid. Am J Otol. 1997;18(6 Suppl):S140-41. [PMID: 9391635]

71. Ching TY, Incerti P, Hill M, Brew J. Fitting and evaluating a hearing aid for recipients of a unilateral cochlear implant: The NAL approach. Part 2. Bimodal hearing should be standard for most cochlear implant users. Hear Rev. 2004;11(8):32-40,63.

72. Müller J, Schön F, Helms J. Speech understanding in quiet and noise in bilateral users of the MED-EL COMBI 40/40+ cochlear implant system. Ear Hear. 2002;23(3):198-206. [PMID: 12072612]

73. Schön F, Müller J, Helms J. Speech reception thresholds obtained in a symmetrical four-loudspeaker arrangement from bilateral users of MED-EL cochlear implants. Otol Neurotol. 2002;23(5):710-14. [PMID: 12218624]

74. Ramsden R, Greenham P, O'Driscoll M, Mawman D, Proops D, Craddock L, Fielden C, Graham J, Meerton L, Verschuur C, Toner J, McAnallen C, Osborne J, Doran M, Gray R, Pickerill M. Evaluation of bilaterally implanted adult subjects with the Nucleus 24 cochlear implant system. Otol Neurotol. 2005;26(5):988-98. [PMID: 16151348]

75. Senn P, Kompis M, Vischer M, Haeusler R. Minimum audible angle, just noticeable interaural differences and speech intelligibility with bilateral cochlear implants using clinical speech processors. Audiol Neurootol. 2005; 10(6):342-52. [PMID: 16103645]

76. Schleich P, Nopp P, D’Haese P. Head shadow, squelch, and summation effects in bilateral users of the MED-EL COMBI 40/40+ cochlear implant. Ear Hear. 2004;25(3): 197-204. [PMID: 15179111]

77. Firszt JB, Reeder RM, Holden LK, Potts LG, Mispagel K, Holstad B, et al., editors. Does unilateral acoustic or electric hearing maintain the contralateral deaf ear for successful cochlear implantation? In: Proceedings of the 2007 Conference on Implantable Auditory Prostheses; 2007 Jul 15; Lake Tahoe, CA. Los Angeles (CA): House Ear Institute; 2007.

78. Tyler RS, Gantz BJ, Rubinstein JT, Wilson BS, Parkinson AJ, Wolaver A, Preece JP, Witt S, Lowder MW. Threemonth results with bilateral cochlear implants. Ear Hear. 2002;23(1 Suppl):80S-89S. [PMID: 11883771]

79. Gantz BJ, Tyler RS, Rubinstein JT, Wolaver A, Lowder M, Abbas P, Brown C, Hughes M, Preece JP. Binaural cochlear implants placed during the same operation. Otol Neurotol. 2002;23(2):169-80. [PMID: 11875346]

80. Ricketts TA, Grantham DW, Ashmead DH, Haynes DS, Labadie RF. Speech recognition for unilateral and bilateral cochlear implant modes in the presence of uncorrelated noise sources. Ear Hear. 2006;27(6):763-73. [PMID: 17086085]

81. Litovsky R, Parkinson A, Arcaroli J, Sammeth C. Simultaneous bilateral cochlear implantation in adults: A multicenter clinical study. Ear Hear. 2006;27(6):714-31. [PMID: 17086081]

82. Killion MC, Niquette PA, Gudmundsen GI, Revit LJ, Banerjee S. Development of a quick speech-in-noise test for measuring signal-to-noise ratio loss in normal-hearing and hearing-impaired listeners. J Acoust Soc Am. 2004; 116(4 Pt 1):2395-2405. [PMID: 15532670] Erratum in: J Acoust Soc Am. 2006;119(3)1888.

83. Buss E, Pillsbury HC, Buchman CA, Pillsbury CH, Clark MS, Haynes DS, Labadie RF, Amberg S, Roland PS, 
Kruger P, Novak MA, Wirth JA, Black JM, Peters R, Lake J, Wackym PA, Firszt JB, Wilson BS, Lawson DT, Schatzer R, D’Haese PS, Barco AL. Multicenter U.S. bilateral MED-EL cochlear implantation study: Speech perception over the first year of use. Ear Hear. 2008; 29(1):20-32. [PMID: 18091099]

84. Grantham DW, Ashmead DH, Ricketts TA, Labadie RF, Haynes DS. Horizontal-plane localization of noise and speech signals by postlingually deafened adults fitted with bilateral cochlear implants. Ear Hear. 2007;28(4):524-41. [PMID: 17609614$]$

85. Laszig R, Aschendorff A, Stecker M, Müller-Deile J, Maune S, Dillier N, Weber B, Hey M, Begall K, Lenarz T, Bettmer RD, Böhm M, Steffens T, Strutz J, Linder T, Probst R, Allum J, Westhofen M, Doering W. Benefits of bilateral electrical stimulation with the Nucleus cochlear implant in adults: 6-month postoperative results. Otol Neurotol. 2004;25(6):958-68. [PMID: 15547426]

86. Litovsky RY, Parkinson A, Arcaroli J, Peters R, Lake J, Johnstone P, Yu G. Bilateral cochlear implants in adults and children. Arch Otolaryngol Head Neck Surg. 2004; 130(5):648-55. [PMID: 15148192]

87. Neuman AC, Haravon A, Sislian N, Waltzman SB. Sounddirection identification with bilateral cochlear implants. Ear Hear. 2007;28(1):73-82. [PMID: 17204900$]$

88. Nopp P, Schleich P, D’Haese P. Sound localization in bilateral users of MED-EL COMBI 40/40+ cochlear implants. Ear Hear. 2004;25(3):205-14. [PMID: 15179112]

89. Schoen F, Mueller J, Helms J, Nopp P. Sound localization and sensitivity to interaural cues in bilateral users of the MED-EL COMBI 40/40+ cochlear implant system. Otol Neurotol. 2005;26(3):429-37. [PMID: 15891645]

90. Seeber BU, Fastl H. Localization cues with bilateral cochlear implants. J Acoust Soc Am. 2008;123(2):1030-42. [PMID: 18247905]

91. Van Hoesel R, Ramsden R, O’Driscoll M. Sound-direction identification, interaural time delay discrimination, and speech intelligibility advantages in noise for a bilateral cochlear implant user. Ear Hear. 2002;23(2):137-49. [PMID: 11951849]

92. Van Hoesel RJ. Exploring the benefits of bilateral cochlear implants. Audiol Neurootol. 2004;9(4):234-46. [PMID: 15205551$]$

93. Van Hoesel RJ, Tyler RS. Speech perception, localization, and lateralization with bilateral cochlear implants. J Acoust Soc Am. 2003;113(3):1617-30. [PMID: 12656396]

94. Verschuur CA, Lutman ME, Ramsden R, Greenham P, O’Driscoll M. Auditory localization abilities in bilateral cochlear implant recipients. Otol Neurotol. 2005;26(5): 965-71. [PMID: 16151344]

95. Lawson DT, Wilson BS, Zerbi M, Van den Honert C, Finley CC, Farmer JC Jr, McElveen JT Jr, Roush PA. Bilateral cochlear implants controlled by a single speech processor. Am J Otol. 1998;19(6):758-61. [PMID: 9831150]

96. Van Hoesel RJ, Clark GM. Speech results with a bilateral multi-channel cochlear implant for spatially separated signal and noise. Aust J Audiol. 1999;21:23-28.

97. Van Hoesel RJ. Sensitivity to binaural timing in bilateral cochlear implant users. J Acoust Soc Am. 2007;121(4): 2192-2206. [PMID: 17471733]

98. Grantham DW, Ashmead DH, Ricketts TA, Haynes DS, Labadie RF. Interaural time and level difference thresholds for acoustically presented signals in post-lingually deafened adults fitted with bilateral cochlear implants using CIS+ processing. Ear Hear. 2008;29(1):33-44. [PMID: 18091105$]$

99. Long CJ, Eddington DK, Colburn HS, Rabinowitz WM. Binaural sensitivity as a function of interaural electrode position with a bilateral cochlear implant user. J Acoust Soc Am. 2003;114(3):1565-74. [PMID: 14514210]

100. Parkinson AJ. Advantages related to the use of bilateral microphones in patients using cochlear implants [thesis]. Iowa City (IA): University of Iowa; 2006.

101. Balkany T, Boggess W, Dinner B. Binaural cochlear implantation: Comparison of 3M/House and Nucleus 22 devices with evidence of sensory integration. Laryngoscope. 1988;98(10):1040-43. [PMID: 3172948]

102. Tyler RS, Dunn CC, Witt SA, Noble WG. Speech perception and localization with adults with bilateral sequential cochlear implants. Ear Hear. 2007;28(2 Suppl):86S-90S. [PMID: 17496655]

103. Dorman MF, Dahlstrom L. Speech understanding by cochlear-implant patients with different left- and right-ear electrode arrays. Ear Hear. 2004;25(2):191-94. [PMID: 15064664$]$

104. Dunn CC, Tyler RS, Witt SA, Gantz BJ. Effects of converting bilateral cochlear implant subjects to a strategy with increased rate and number of channels. Ann Otol Rhinol Laryngol. 2006;115(6):425-32. [PMID: 16805373]

105. Wackym PA, Runge-Samuelson CL, Firszt JB, Alkaf FM, Burg LS. More challenging speech-perception tasks demonstrate binaural benefit in bilateral cochlear implant users. Ear Hear. 2007;28(2 Suppl):80S-85S. [PMID: 17496654$]$

Submitted for publication August 10, 2007. Accepted in revised form May 27, 2008. 